\title{
How do diversity and functional nestedness of bird communities respond to changes in the landscape caused by eucalyptus plantations?
}

\author{
L. I. Jacoboski ${ }^{1,2}$, V. J. Debastiani ${ }^{1}$, A. de Mendonça-Lima ${ }^{1}$ and S. M. Hartz ${ }^{1}$ \\ 1Programa de Pós-Graduação em Ecologia. Universidade Federal do Rio Grande do Sul (UFRGS). Av. Bento \\ Gonçalves 9500, CEP 91501-970. Porto Alegre, Rio Grande do Sul, Brazil \\ ${ }^{2}$ Corresponding author: Laboratório de Ecologia de Populações e Comunidades, Programa de Pós-Graduação em \\ Ecologia. Universidade Federal do Rio Grande do Sul (UFRGS). Av. Bento Gonçalves 9500. Prédio 43422, sala 209, \\ Caixa Postal 15007, CEP 91501-970, Porto Alegre, Rio Grande do Sul, Brazil. Tel: +(55) 513308 6634. E-mail: \\ lucilene.jacoboski@yahoo.com.br
}

Keywords: Avian fauna, Functional traits, Nestedness, Silviculture.

\begin{abstract}
Studies of functional diversity can help to understand processes that determine the presence of species in different habitats. Measurement of functional diversity in silviculture areas is important because different functional traits can show different responses to this landscape alteration, and therefore ecological functions can be affected. This study evaluated functional and taxonomic differences in bird assemblages in a native forest and eucalyptus plantations, and also assessed the functional nestedness of the bird species. We censused birds in eucalyptus plantations of four different ages, and also in a native forest. The results showed higher functional and taxonomic diversity of birds in the native forest than in plantations and higher similarity of functional traits between plantations of different ages. The high functional diversity in the native forest indicates a greater variety of functional traits, resulting in greater functional complementarity than in plantations. The association of some traits with the native forest, such as nectarivory and foraging in air, indicates the importance of native habitats in maintaining species and functions related to such traits. Already, species traits in eucalyptus plantations represent a subset of those that were recorded in the native forest, indicating that some functions are maintained in plantations. Our results demonstrate that the species occurrence in the plantations and native forest is determined by species traits. Thus, the maintenance of some functions in plantations is provided, although there is a higher functional diversity in native forest.
\end{abstract}

Nomenclature: Piacentini et al. (2015).

Abbreviations: CWM-Community Weighted Mean traits, HFBN-Horto Florestal Barba Negra, NF-Native Forest, NODFNestedness metric based on Overlap and Decreasing Fill, PPA-Permanent Preservation Area.

\section{Introduction}

The use of indices based on the functional composition of assemblages is important to evaluating the stability of communities and their habitats (Guerrero et al. 2011, Newbold et al. 2012). The stability of a community depends on the maintenance of the functions performed by organisms of different functional groups, which respond differently to environmental conditions (Walker 1995). These functions are performed by traits of organisms, that can be ecological, physiological and morphological characteristics (Petchey and Gaston 2006, Cianciaruso et al. 2009, Flynn et al. 2009). Species traits may reflect environmental conditions as many traits respond to changes in resource availability (Cleary et al. 2007). Thus, measures of functional diversity help to understand the effects of changes in biodiversity on ecosystem processes (Tilman et al. 1997, Petchey and Gaston 2006).

The maintenance of birds' functional diversity is important as birds provide important functions to the ecosystems, including pollination, dispersal of seeds, and predation of invertebrates and small mammals (Tscharntke et al. 2008, Luck et al. 2013). However, the replacement of native habitats by tree plantations can change the functional characteristics of birds assemblages. Eucalyptus (Eucalyptus spp.) is exotic in tropical regions of South America. Eucalyptus plantations have become a concern in Brazil, Uruguay and Argentina due to their rapid expansion, especially in native grassland ecosystems (Marsden et al. 2001, Barlow et al. 2007, Aspiroz et al. 2012). This practice decreases habitat heterogeneity, resulting in the loss and homogenisation of biodiversity (Filloy and Bellocq 2007, Brockerhoff et al. 2008). Low bird species diversity is commonly found in plantations, as are communities that are mainly characterised by habitat generalists (Volpato et al. 2010). This low diversity is related to changes in vegetation type and structure, spatial distribution of habitat components (i.e., connectivity level), intra- or interspecific interactions (such as competition and predation) and food, nest availability (Luck et al. 2012). Thus, forest birds depend 
on resources supplied by forests, but also the functional viability of forests depends on ecological benefits supplied by birds, including pollination, seed dispersal and predator control (Gray et al. 2007).

Each bird species responds to habitat change according to a combination of its morphological and ecological traits. Some of these traits are more closely correlated with environmental changes, including body size, fecundity, diet, and habitat extent (Newbold et al. 2012). Among these, bird diet is considered a key trait to understand how an individual responds to changes in the environment and how it affects ecosystem function, and is also strongly related to the risk of bird species extinction (Sekercioglu 2006, Luck et al. 2013). Thus, measurements based on functional diversity allow a preliminary evaluation of functions performed by species in a particular ecosystem, as these relations cannot be detected only by counting species (de Souza et al. 2013).

As a complementary measure of functional diversity, recently Melo et al. (2014) have introduced an extension of the NODF (Nestedness Overlap and Decreasing Fill) (AmeidaNeto et al. 2008) index, termed treeNODF to evaluate functional nestedness. Functional nestedness occurs when the species traits of a community represent a subset of species traits of a community with more trait diversity, in other words, when part of the traits is shared between communities (Melo et al. 2014). The functional nestedness must take into account the similarity in species traits, because traditional nestedness metrics ignore the possibility that species that share many functional traits can be redundant in an ecological process, or may show high niche overlap (Melo et al. 2014). Thus, the use of species traits allow us to understand how species affect ecosystem stability and the degree to which species compete for resources (Melo et al. 2014).

In this study, our goal was to evaluate whether eucalyptus plantations affect the functional diversity of bird communities and if species traits of plantations are nested in relation to species traits of native forest. We tested two hypotheses: 1) both functional diversity and taxonomic diversity are higher in the native forest because of the higher structural heterogeneity in native habitats; 2) species traits in eucalyptus plantations represent a subset of traits in relation to species from the native forest, resulting in functional nestedness, because some species of plantations are shared with the native forest (Jacoboski et al. 2016).

\section{Material and methods}

\section{Study area}

This study was conducted in the Horto Florestal Barba Negra (HFBN), owned by the company CMPC Celulose Riograndense. The HFBN is a silviculture farm for pulpwood production. This area is located in Barra do Ribeiro municipality, between $30^{\circ} 27^{\prime} 55$ and $30^{\circ} 26^{\prime} 32 \mathrm{~S}$, and $051^{\circ} 16^{\prime} 04$ and $051^{\circ} 05^{\prime} 44 \mathrm{~W}$, Rio Grande do Sul state, Brazil. The HFBN area is a peninsula bordered on the north and northeast by
Guaíba Lake, on the south and southeast by Patos Lagoon, and on the west by cropland and livestock pastures (Sydow 2010).

The regional climate is predominantly humid subtropical (Köppen's Cfa). The mean annual temperature is $19.3^{\circ} \mathrm{C}$ and the annual precipitation is about $1322 \mathrm{~mm}$, according to Köppen's climate classification (Moreno 1961).

The total area of HFBN is 10,600 ha, with 2,400 ha of permanent preservation area (PPA), and a eucalyptus plantation on the remaining 8,200 ha. In Brazil, PPAs are legally protected areas. The sampling in the native forest was conducted on Formiga Hill, which is located in the PPA. The forest vegetation consists of Semideciduous Atlantic Forest, comprising species of Deciduous Forest and Dense Ombrophilous Forest, with the predominance of a formation called "restinga" (Leite 2002). "Restinga" forest presents height between 6-12 m, many epiphytes, predominance of Myrtaceae species, dense understory and the occurrence of some characteristic species, among them Ficus organensis Miq. (Waechter 1985).

In the HFBN, the eucalyptus stands are planted in a mosaic (plantations of several ages), to avoid large areas with same-aged trees. The trees are cut about seven years after planting, but older plantations are also found in HFBN. The understory vegetation is not managed, however, it is very sparse and often absent. In plantations of up to three years old, the understory vegetation is characterized by grass and other herbaceous species, and in older plantations predominate some shrubs.

\section{Experimental design}

Sampling was conducted in the commercial eucalyptus plantations and in the native restinga forest. Eucalyptus plantations were classified in four categories according to their age. Each plantation age and native forest were considered as a treatment. Treatment 1 (T1) - plantations up to 3 years old. Treatment 2 (T2) - plantations from 3 to 7 years. Treatment 3 (T3) - plantations from 7 to 12 years. Treatment 4 (T4) plantations from 14 to 25 years. Treatment 5 - native restinga forest (NF). In each treatment, 10 sampling sites were established, except in the native forest where only one site was used for sampling. This was necessary since other areas of NF in the HFBN were too small to use this method. The sites were designated a priori with the criterion that there was no contiguity between plantations (no connection). The choice of all sites takes into account adequate size to support the sampling method.

At each treatment 30 counting points were established, totalling 150 points. The point count method is well suited for bird studies in forest ecosystems, because most of the records are made by listening to bird vocalizations, thus involving the whole community of birds (Develey 2003). The point counts were positioned randomly, while maintaining a minimum distance of $200 \mathrm{~m}$ between points, according Bibby et al. (1992), this distance is ideal to ensure statistical independence between points. We remained for 10 minutes 
at each point. During this period, every bird species seen or heard was recorded. Each point count had a fixed radius of $50 \mathrm{~m}$, as according to Anjos et al. (2001), most species can only be heard up to $40-50 \mathrm{~m}$ from the observer. We avoided plantation and forest edges. Counts started 30 minutes after sunrise and continued for 3 hours. Each morning, two sites of two different treatments were sampled. Each treatment area was sampled during different periods of the morning, in the 3 hours of sampling. Sites were sampled only once (without repetition). Sampling was conducted from October through December 2012 (austral spring), which is the breeding season of birds in Brazil. Bird species nomenclature and classification follow Piacentini et al. (2015).

\section{Functional traits of bird species}

Species were characterised in relation to the following traits: body mass, bill length, wing and tail length, trophic category (omnivores, insectivores, frugivores, granivores and nectarivores), foraging substrate (vegetation, soil and air) and nesting substrate (vegetation and soil). These traits were chosen considering the possibility that they would respond to alterations in vegetation structure imposed by silviculture at the study site (Sekercioglu 2012, Luck et al. 2013). The loss of any of these traits can result in loss of essential functions for the ecosystem (i.e., seed dispersal, predation rates, decreased clutch size).

Wing length was measured from the shoulder joint to the tip of the largest primary feather, with the wing closed (Roos 2010). Tail length was measured from the tip of the longest feather to its point of insertion in the skin. Bill length was measured from the tip of the bill to its insertion in the skull (Roos 2010). Information related to behavioral traits (trophic category, foraging substrate and nesting substrate) were based on information from the literature (Sick 1997, Del Hoyo et al. 1992-2002, Del Hoyo et al. 2003-2006). Morphological traits were measured on individuals $(n=3)$ from the William Belton Ornithological Collection (Coleção Ornitológica William Belton) of the Fundação ZooBotânica do Rio Grande do Sul. Before the functional diversity analysis, we performed a correlation analysis between traits, those that were correlated were excluded from the analysis.

\section{Data analysis}

We estimated species richness for the eucalyptus plantations and native forest based on the Chao 2 estimator (Colwell and Coddington 1994), with 100 randomizations, using EstimateS 9.1.0 (Colwell 2013). To measure the taxonomic diversity we used Simpson's diversity index (Magurran 1988). Data were organised into the following matrices: matrix $\mathrm{B}$ - species described by traits; matrix $\mathrm{W}$ - sampling units described by species. We calculated community weighted mean traits (CWM) for birds. CWM trait values represent the mean of each trait weighted by the relative abundance of the individual bird species representing each trait value (Garnier et al. 2004). Such metric informs us on dominant traits in the community. CWM trait values were computed by matrix multiplication $\mathrm{T}=\mathrm{WB}$ (Pillar et al. 2009). Functional diversity (FD) was estimated by Rao's quadratic entropy (Rao 1982), which is informative on the extent of trait dissimilarity among taxa in the community (Pillar et al. 2009). In this way FD is calculated as the sum of the dissimilarities based on traits weighted by the product of the relative abundances. Taxonomic and functional diversity were both calculated in Syncsa 2.6.9 software (Pillar and Duarte 2010).

We removed the influence of differences in species body mass on morphological traits (wing, bill and tail), which cause allometry in these traits. Allometric relations occur as a result of interactions of physical and geometric constraints during organism development, affecting attributes ranging from the ratio of biological structures (such as limbs and organs) to population dynamics (West et al. 1997). Therefore, as traits must be independent of organism body mass, they need to be transformed. Constraints on growth are usually on the order of the 1/3 exponent (West et al. 1997), and thus the traits were transformed by dividing the trait value by the cube root of the respective species body mass (West et al. 1997).

To compare the functional and taxonomic diversity between the eucalyptus plantations of different ages and the native forest, analysis of variance (ANOVA) was used. In order to identify the relationship between the traits and treatments, a principal coordinates analysis ( $\mathrm{PCoA}$ ) was performed with matrix T. The analysis of variance and PCoA were performed in Multiv 2.63 software (Pillar 2006).

To test the functional nestedness we used the treeNODF index. The treeNODF index is calculated in a similar manner to traditional NODF, but instead of using species richness of sites to estimate the degree of nestedness, the branch lengths of a tree-like object are used (i.e., species richness/ species incidence is replaced with the branch lengths of a tree-like object or functional dendrogram) (Melo et al. 2014). To test functional nestedness between treatments, we first constructed a functional dendrogram from the matrix of the composition of species and their traits using Gower distance. Next, we calculated functional nestedness from the functional dendrogram using the $\mathrm{R}$ package CommEcol, using the function treeNODF. We used the null model permRows, which randomly reorders rows of the matrix and calculates treeNODF values for each rows-reordered matrix (Melo et al. 2014). A useful feature of treeNODF is that it can be partitioned into two components: 1) S.Fraction - the composition component of the index, i.e., the fraction of treeNODF that would be observed if all species were equally related, and 2) topoNODF - the fraction of the treeNODF value due to the topology of the tree (e.g., the dendrogram). Examining each component separately allows for additional inferences regarding the nestedness of ecological communities (Melo et al. 2014).To this analysis, matrix of communities and sampling units were organised in descending order forest heterogeneity (from a native forest for the youngest plantations 3 years old). These analyses were performed in the R environment ( $R$ Development Core Team 2012). 


\section{Results}

A total of 71 species were identified in the five sampled groups (Appendix). The number of species estimated by Chao2 for each treatment was very close to the number of species observed in the samples (Table 1).

Functional diversity of bird species, measured with the Rao's quadratic entropy, differed significantly between groups $(\mathrm{Q}=0.07, \mathrm{p}=0.008$, Fig. $1 \mathrm{~A})$, with a higher functional diversity index in the native forest than in the eucalyptus plantations of different ages, and without significant differences among the plantations. Taxonomic diversity showed this same pattern of higher species diversity in the native forest $(\mathrm{Q}=0.23, \mathrm{p}=0.01$, Fig. 1B).

The PCoA showed an association of species traits with the habitat. Traits related to younger plantations were foraging and nesting in soil, granivory and omnivory. Older plantations were associated with frugivory, insectivory and foraging in vegetation. The native forest demonstrated associations with nectarivory, foraging in air and nesting in vegetation (Fig. 2).

Our results showed nestedness of functional traits among species from the eucalyptus plantations in relation to the native forest $($ treeNODF $=46.53, \mathrm{p}=0.001$, Table 2 ).

\section{Discussion}

Functional and taxonomic diversity of birds was highest in the native forest, confirming our initial hypothesis. This demonstrates that species occurring in the native forest show a greater variety of traits, and at least in part, a unique combination of traits, reflected by the higher diversity and availability of resources in the native forest. On the other hand, some functions were lost in silviculture areas, independently

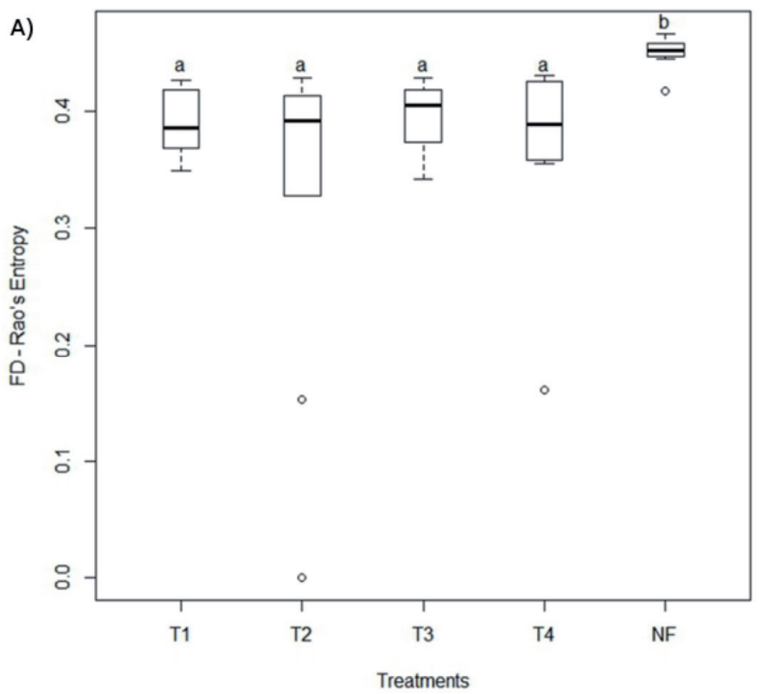

Table 1. Number of species of birds observed in each treatment and estimated number of species by Chao 2 with $95 \%$ confidence interval. T1: eucalyptus plantations up to 3 years old, T2: eucalyptus plantations from 3 to 7 years, T3: eucalyptus plantations from 7 to 12 years, T4: eucalyptus plantations from 14 to 25 years, NF: native forest.

\begin{tabular}{lcc}
\hline Treatments & Observed species & Chao 2 estimate $(95 \% \mathrm{CI})$ \\
\hline $\mathrm{T} 1$ & 41 & $45(49-78)$ \\
$\mathrm{T} 2$ & 33 & $43(26-63)$ \\
$\mathrm{T} 3$ & 30 & $40(25-51)$ \\
$\mathrm{T} 4$ & 30 & $31(23-46)$ \\
$\mathrm{NF}$ & 56 & $67(49-78)$ \\
\hline
\end{tabular}

Table 2. treeNODF analyses of birds in native forest and eucalyptus plantations. S.Fraction measuring nestedness based on composition, and topoNODF measuring nestedness based on tree topology. M: Mean of statistics obtained under a null model (999 randomizations), SD: Standard deviation of statistics obtained under a null model, Z: (Observed - Mean)/SD.

\begin{tabular}{lccccc}
\hline & Obs & $\mathrm{M}$ & $\mathrm{SD}$ & $\mathrm{Z}$ & $\mathrm{P}$ \\
\cline { 2 - 6 } treeNodf & 46.53 & 35.59 & 3.52 & 3.10 & 0.001 \\
S.Fraction & 29.27 & 22.19 & 2.32 & 3.04 & 0.001 \\
topoNodf & 17.26 & 13.40 & 1.37 & 2.81 & 0.003 \\
\hline
\end{tabular}

of plantation age, showing a high similarity of traits. This similarity reflects the reduced availability of resources for the species in plantations, due in part to its less developed or absent understory. Thereby, only species that have traits that easily adapt to different habitat conditions persist in plantations. Results of study by Edwards et al. (2013) and Flynn et al. (2009) also demonstrated that silviculture is associated

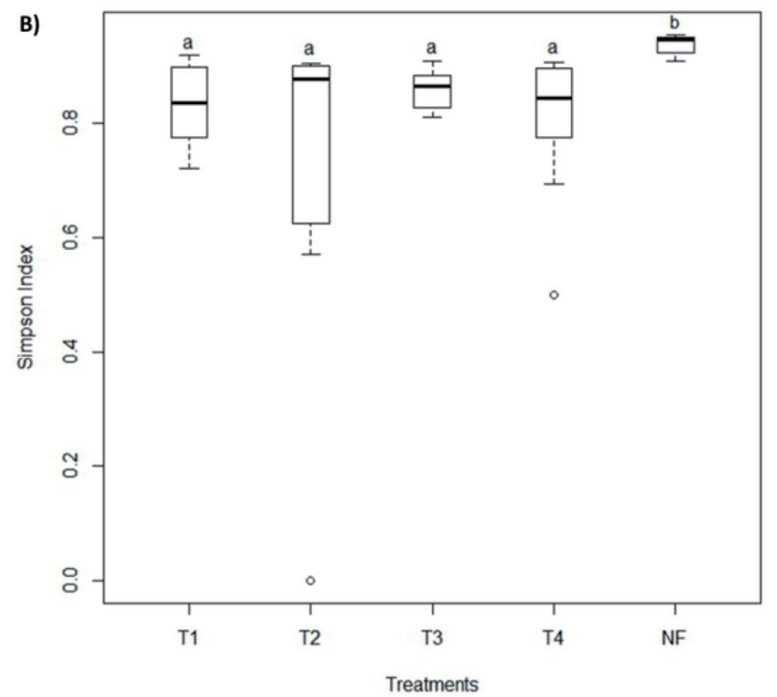

Figure 1. Box plots for functional diversity values (FD) measured by Rao's entropy (A) and Simpson's taxonomic diversity index (B), showing the difference between the sampled treatments with their maximum and minimum values and standard error. Different letters indicate significant differences between treatments. Abbreviations as in Table 1. 


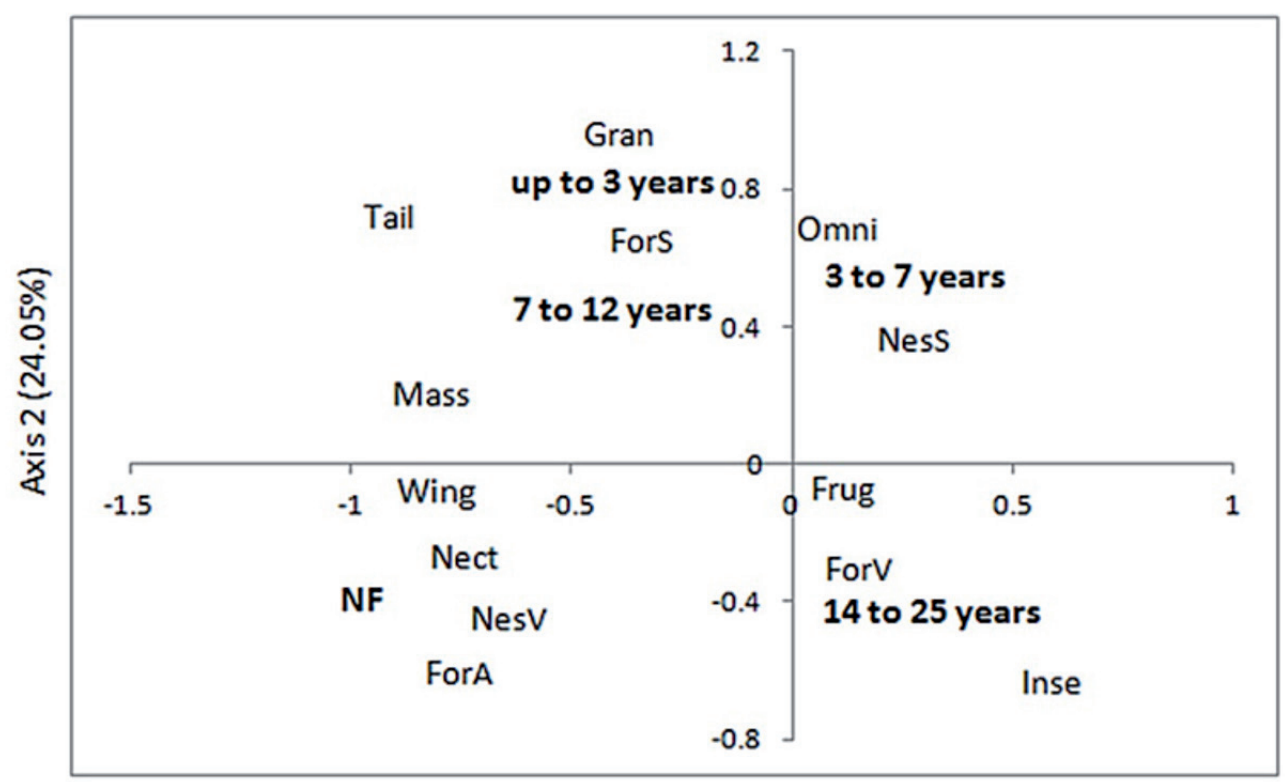

Axis $1(35.47 \%)$

Figure 2. Principal Coordinates Analysis ordination on the first and second axes, showing the array of the areas (bold) and functional traits for bird species distribution. ForA (foraging in air), NestV (nesting vegetation), Nect (nectarivore), Mass, Tail, ForS (foraging on soil), Gran (granivore), Omni (omnivore), NesS (nesting on soil), Frug (frugivore), ForV (foraging in vegetation), Inse (insectivore). Further abbreviations as in Table 1.

with significant declines in the functional diversity of birds, suggesting the effect of an environmental filter. Already, a higher functional diversity can help to attenuate effects on communities caused by several environmental changes (Luck et al. 2013), since there is greater complementarity in the functions performed by species.

The association of some species traits with the native forest (nectarivory, nesting in vegetation, foraging in air) indicates that these traits are related to more structurally complex environments (Sekercioglu 2006). These associations also provide information about the characteristics of species that can be more strongly affected in silviculture systems, as the response of each species to the environment is measured by its traits and degree of specialisation. Some species have functional roles that are more sensitive to environmental changes in space and time than others (Wells et al. 2012). The use of these indices may make it possible to anticipate the effects of the loss of these species on ecological functions (Trindade-Filho and Loyola 2010, Boyer and Jetz 2014).

Our results also show the functional nestedness of traits, since the species traits from the plantations are a subset of those from the native forest. Only species with certain traits are adapted to the habitat conditions of silviculture areas, in other words, are independent of structure and amount of vegetation. Thus, species traits can determine their presence in plantations, as main or occasional habitats for refuge, landing site (Jacoboski et al. 2016). This result is consistent, because silviculture supplies fewer resources for species, such as appropriate substrates for nesting and foraging (Motta-Junior, 1990; Kowk and Corlett, 2000), benefiting species traits of habitat generalists and of those associated with forest edges.
A stress gradient may generate functional nestedness if conditions at increasingly stressed sites select species with a restricted set of traits that allow them tho survive (Melo et al. 2014).

Some factors determine the persistence of populations in modified landscapes, such as their mobility, dispersal and ability to use resources, but mainly on their ability to adapt to altered environments (Lindenmayer et al. 2003, Sekercioglu 2012). The changes in land use represent a serious threat to forest-bird specialists, with declines in species with particular combinations of ecological traits, affecting the supply of ecosystem services (Flynn et al. 2009, Newbold et al. 2012). According to Sekercioglu (2006) and Gray et al. (2007), the main impact of these changes on ecosystem functioning is related to the feeding specialisation of birds, as these have important functional roles including pollination, seed dispersal and predation.

Our results demonstrate both a low functional diversity in silviculture areas and a significant functional nestedness between plantations and native forest. Thus, the species presence of the plantations is determined by the combination of traits of each of the species. However, we do not know to what degree bird species use plantations (occasional or permanent). It is still necessary to investigate questions mainly related to species reproduction, in order to evaluate the potential of these areas to provide a habitat for birds during their life cycle and to contribute to the persistence of their populations.

On the other hand, species with traits associated with native forest deserve attention, because they become vulner- 
able in environments modified by silviculture. We therefore emphasize the importance of using functional measures to recognize bird species traits that are most threatened by the changes caused by exotic monocultures in native forest ecosystems in the Neotropics. The studies of species traits can help us in future conservation and management plans, so that not only the species of conservation concern are protected but the entire ecosystem that depends on the functions performed by these species.

Acknowledgements: This paper is dedicated to the memory of our colleague and coauthor, A. de Mendonça-Lima.

We thank CMPC Celulose Riograndense for financial and logistical support. We are grateful to E. Araújo, who provided information about the study area, and to R. Didio dos Santos, C. Saturno and C. Bauchpiess, who helped in the field work. We also thank Drs L. dos Anjos, R. Dias and J. K. Felix Mähler Jr. for their valuable suggestions on the final version of the manuscript. Conselho Nacional de Desenvolvimento Científico e Tecnológico (CNPq) supplied scholarships to LIJ (M.Sc.). SMH holds a research grant from $\mathrm{CNPq}$, process 306816/2010-5.

\section{References}

Almeida-Neto, M, P. Guimarães, P.R. Guimarães Jr., R.D. Loyola and W. Ulrich. 2008. A consistent metric for nestedness analysis in ecological systems: reconciling concept and measurement. Oikos 117: 1227-1239.

Anjos, L. dos, 2001. Bird communities in five Atlantic forest fragments in southern Brazil. Ornitol. Neotrop. 12: 11-27.

Aspiroz, A.B., J.P. Isacch, R.A. Dias, A.S. Giacomo, C.S. Fontana and C.M. Palarea. 2012. Ecology and conservation of grassland birds in southeastern South America: a review. J. Field Ornithol. 83: $217-246$.

Barlow, J., L. A. M. Mestre, T. A. Gardner and C. A. Peres. 2007. The value of primary, secondary and plantation forests for Amazonian birds. Biol. Conserv. 36: 212-231.

Bibby, C.J., N.D. Burgess, and D.A. Hill. 1992. Bird Census Techniques. Academic Press, London.

Boyer, A.G. and W. Jetz. 2014. Extinctions and the loss of ecological function in island bird communities. Global Ecol. Biogeogr. 23: 679-688.

Brockerhoff, E.G., H. Jactel, J.A. Parrotta, C.P. Quine and J. Sayer. 2008. Plantation forests and biodiversity: oxymoron or opportunity? Biodivers. Conserv. 17: 925-951.

Cianciaruso, M.V., I.A. Silva and M.A. Batalha. 2009. Diversidades filogenética e funcional: novas abordagens para a ecologia de comunidades. Biota Neotrop. 9: 93-103.

Cleary, D.F.R., T.J.B. Boyle, T. Setyawati, C.D. Anggraeni, E.E. Van Loon and S.B. Menken. 2007. Bird species and traits associated with logged and unlogged forest in Borneo. Ecol. Appl. 17: 1184-1197.

Colwell, R.K. 2013. EstimateS 9.1.0. Retrieved from: http://viceroy. eeb.uconn.edu/estimates/index.html/ on 22/08/2014.

Colwell, R.K. and J.A. Coddington. 1994. Estimating terrestrial biodiversity through extrapolation. Phil. Trans. R. Soc. Lond. B. Biol. Sci. 345: 101-118.
Del Hoyo, J., A. Elliot and J. Sargatal. 1992-2002. Handbook of the Birds of the World. Lynx, Barcelona. (Ostrich to ducks, vols. $1-7)$.

Del Hoyo, J., A. Elliot and D. Christie. 2003-2006. Handbook of the Birds of the World. Lynx, Barcelona. (Broadbills to tapaculos, vols. 8-11).

de Souza, D., D.F.B. Flynn, F. De Clerck, R.K. Rosenbaum, H.M. Lisboa and T. Koellner. 2013. Land use impacts on biodiversity in LCA: proposal of characterization factors based on functional diversity. Int. J. Life Cycle Assess. 18: 1231-1242.

Develey, P.F. 2003. Métodos para estudos com aves. In: Cullen Jr., L., R. Rudran and C. Valladares-Padua (eds), Métodos de estudos em Biologia da Conservação \& Manejo da Vida Silvestre. Editora UFPR, Curitiba, pp. 153-168.

Edwards, F.A., D.P. Edwards, K.C. Hamer and R.G. Davies. 2013. Impacts of logging and conversion of rainforest to oil palm on the functional diversity of birds in Sundaland. Ibis 155: 313-326.

Filloy, J. and M.I. Bellocq. 2007. Respuesta de las aves rapaces al uso de la tierra: un enfoque regional. Hornero 22: 131-140.

Flynn D.F.B., M. Gogol-Prokurat, T. Nogeire, N. Molinari, B.T. Richers, B.B. Lin, N. Simpson, M.M. Mayfield and F. de Clerck. 2009. Loss of functional diversity under land use intensification across multiple taxa. Ecol. Lett. 12: 22-33.

Garnier, E., Cortez, J., Billes, G., Navas, M.L., Roumet, C., M. Debussche, G. Laurent, A. Blanchard, D. Aubry, A. Bellmann, C. Neill and J.P. Toussaint. 2004. Plant functional markers capture ecosystem properties during secondary succession. Ecology 85: $2630-2637$.

Gray, M.A., S.L. Baldauf, P.J. Mayhew and J.K. Hill. 2007. The response of avian feeding guilds to tropical forest disturbance. Conserv. Biol. 21: 133-141.

Guerrero I., M.B. Morales, J.J. Oñate, T. Aavik, J. Bengtsson, F. Berendse, L.W. Clement, C. Dennis, S. Eggers, M. Emmerson, C. Fischer, A. Flohre, F. Geiger, V. Hawro, P. Inchausti, A. Kalamees, R. Kinks, J. Liira, L. Meléndez, T. Pärt, C. Thies and T. Tscharntke. 2011. Taxonomic and functional diversity of farmland bird communities across Europe: effects of biogeography and agricultural intensification. Biodivers. Conserv. 20: 3663-3681.

Jacoboski, L.I., A. Mendonça-Lima and S.M. Hartz. 2016. Structure of bird communities in eucalyptus plantations: nestedness as a pattern of species distribution. Braz. J. Biol. (in press).

Kwok, H.K. and R.T. Corlett. 2000. The bird communities of a natural secondary forest and a Lophostemon confertus plantation in Hong Kong, South China. For. Ecol. Manage. 130: 227-234.

Leite, P.F. 2002. Contribuição ao conhecimento fitoecológico do sul do Brasil. Ciência Ambiental 24: 51-73.

Lindenmayer, D.B., S. McIntyre and J. Fischer. 2003. Birds in eucalypt and pine forests: landscape alteration and its implications for research models of faunal habitat use. Biol. Conserv. 110: 45-53.

Luck, G.W., S. Lavorel, S. McIntyre and K. Lumb. 2012. Improving the application of vertebrate trait-based frameworks to the study of ecosystem services. J. Anim. Ecol. 81: 1065-1076.

Luck, G.W., A. Carter and L. Smallbone. 2013. Changes in bird functional diversity across multiple land uses: interpretations of functional redundancy depend on functional group identity. PLoS ONE 8: 63671-63682.

Magurran, A.E. 1988. Ecological Diversity and Its Measurement. Princeton University Press, Princeton.

Marsden, S.J., M. Whiffin and M. Galetti. 2001. Bird diversity and abundance in forest fragments and Eucalyptus plantations 
around an Atlantic forest reserve, Brazil. Biodivers. Conserv. 10 737-751.

Melo, A.S., M.V. Cianciaruso and M. Almeida-Neto. 2014. treeNODF: nestedness to phylogenetic, functional and other tree-based diversity metrics. Methods Ecol. Evol. 5: 563-572.

Moreno, J.A. 1961. Clima do Rio Grande do Sul. Secretaria da Agricultura, Porto Alegre.

Motta-Junior, J.C. 1990. Estrutura trófica e composição de avifauna de três habitats terrestres na região central do estado de São Paulo. Ararajuba 1: 65-71.

Newbold T., J.P.W. Scharlemann, S.H.M. Butchart, Ç. Sekercioglu, R. Alkemade, H. Booth and D.W. Purves. 2012. Ecological traits affect the response of tropical forest bird species to land-use intensity. Proc. R. Soc. B. 280: 2012-2131.

Petchey, O.L. and K.J. Gaston. 2006. Functional diversity: back to basics and looking forward. Ecol. Lett. 9: 741-758.

Piacentini, V.Q., A. Aleixo, C.A. Agne, G.N. Maurício, J.F. Pacheco, G.A. Bravo, G.R.R. Brito, L.N. Naka, F. Olmos, S. Posso, L.F. Silveira, G.S. Betini, E. Carrano, I. Franz, A.L. Lees, L.M. Lima, D. Pioli, F. Schunck, F.R. Amaral, G.A. Bencke, M. Cohn-Haft, L.F.A. Figueiredo, F.C. Straube and E. Cesari. 2015. Annotated checklist of the birds of Brazil by the Brazilian Ornithological Records Committee. Rev. Bras. Ornitol. 23: 91-298.

Pillar, V.D. 2006. MULTIV: Multivariate exploratory analysis, randomization testing and boostrap resampling, user's guide v. 2 . 4. Universidade Federal do Rio Grande do Sul, Porto Alegre. Retrieved from: http://ecoqua.ecologia.ufrgs.br/arquivos/ Software/Multiv/ on 25/06/2012.

Pillar, V.D. and L.S. Duarte. 2010. A framework for metacommunity analysis of phylogenetic structure. Ecol. Lett. 13: 587-596.

Pillar, V.D., L.D.S Duarte, E.E. Sosinski and F. Joner. 2009 Discriminating traitconvergence and trait-divergence assembly patterns in ecological community gradients. J. Veg. Sci. 20: 334-348.

R Development Core Team. 2012. R: A Language and Environment for Statistical Computing. Vienna: R Foundation for Statistical Computing. https://www.R-project.org/.

Rao, C.R. 1982. Diversity and dissimilarity coefficients-a unified approach. Theor. Popul. Biol. 21: 24-43.

Ross, A.L. 2010. Capturando aves. In: Matter, S.V. Straube F.C., Accordi I., Piacentini V. and Cândido-Jr, J.F. (eds), Ornitologia e Conservação: Ciência Aplicada, Técnicas de Pesquisa e Levantamento. Technical Books Editora, Rio de Janeiro, pp. 77-104.

Sekercioglu, Ç.H. 2006. Increasing awareness of avian ecological function. Trends Ecol. Evol. 21: 464-471.
Sekercioglu, C.H. 2012. Bird functional diversity and ecosystem services in tropical forests, agroforests and agricultural areas. $J$. Ornithol. 153: 153-161.

Sick, H. 1997. Ornitologia Brasileira. Editora Nova Fronteira, Rio de Janeiro.

Sydow, V.G. 2010. Vegetação de sub-bosque em monocultura de Eucalyptus saligna Sm. (Myrtaceae). Dissertação de Mestrado - Universidade Federal do Rio Grande do Sul.

Tilman, D., J. Knops, D. Wedin, P. Reich, M. Ritchie and E. Siemann. 1997. The influence of functional diversity and composition on ecosystem processes. Science 277: 1300-1302.

Trindade-Filho, J. and R.D. Loyola. 2010. O uso de grupos indicadores como atalho para a conservação da biodiversidade. Rev. Biol. Neotrop. 7: 27-38.

Tscharntke, T., C.H. Sekercioglu, T.V. Dietsch, N.S. Sodhi, P. Hoehn and J.M. Tylianakis. 2008. Landscape constraints on functional diversity of birds and insects in tropical agroecosystems. Ecology 89: 944-951.

Volpato, G.H., V.M. Prado and L. Anjos. 2010. What can tree plantations do for forest birds in fragmented forest landscapes? A case study in southern Brazil. Forest Ecol. Manage. 260: 1156-1163.

Waechter, J.L. 1985. Aspectos ecológicos da vegetação de restinga no Rio Grande do Sul, Brasil. Comunicações do Museu de Ciências da PUCRS, Série Botânica 33: 49-68.

Walker, B. 1995. Conserving Diversity Biological through Ecosystem Resilience. Conserv. Biol. 9: 747-752.

Wells K., R. B. O’Hara, S. M. Böhm, S. Gockel, A. Hemp, S.C. Renner, S. Pfeiffer, K. Böhning-Gaese, and E.K.V. Kalko. 2012. Trait-dependent occupancy dynamics of birds in temperate forest landscapes: fine-scale observations in a hierarchical multispecies framework. Anim. Conserv. 15: 626-637.

West, G.B., J.H. Brown and B.J. Enquist. 1997. A general model for the origin of allometric scaling laws in biology. Science 276: 122-126.

Received April 25, 2016

Revised June 9, 2016

Accepted June 20, 2016

\section{Appendix}

Classification of 71 bird species according to body mass, wing length, tail length, bill length, diet, foraging substrate and nesting substrate.

The file may be downloaded from www.akademiai.com. 